\title{
Pensar o Populismo nas Guianas: Limites e Possibilidades
}

luri Cavlak

\author{
Iuri Cavlak \\ Doutor em História pela Universidade \\ Estadual Paulista. Professor do Colegiado \\ de História e dos Programas de Mestrado \\ em Desenvolvimento Regional, Estudos \\ de Fronteira e Ensino de História na \\ Universidade Federal do Amapá. \\ E-mail: iuricavlak@yahoo.com.br
}

\begin{abstract}
Resumo
O presente artigo visa aplicar algumas interpretações históricas presentes no conceito "populismo" para analisar o período recente da História das Guianas, notadamente a República Cooperativa da Guiana, Suriname e Guiana Francesa. O recorte centra-se nos anos da independência e aqueles imediatamente posteriores, no caso dos primeiros, e na segunda metade do século XX, no caso da última. O método utilizado foi o cruzamento de estudos históricos nacionais e internacionais com algumas análises clássicas do populismo latino-americano realizadas por autores brasileiros e argentinos. $\mathrm{O}$ desafio foi estender o conceito, bastante plástico e multifacetado, para uma região sulamericana pouco visitada pela nossa historiografia, objetivando abrir novas possibilidades de entendimento e pesquisa. Ao mesmo tempo que se mostra extremamente difícil abordar o populismo nesses Estados, têm-se algumas semelhanças e paralelismos que podem reforçar a pertinência do conceito.
\end{abstract}

\section{Palavras-chave}

Guiana. Suriname. Guiana Francesa. Populismo. Balanço Historiográfico.

\begin{abstract}
This article intends to apply some historical interpretations present in the concept "populism" to analyze the recent period of Guianas's History, notably the Cooperative Republic of Guyana, Suriname and French Guiana. The focuses is on the years of independence and after, in the case of the first, and the second half of the twentieth century, in the case of the latter. The method used was the crossing of national and international historical studies with some classic analyzes of Latin American populism carried out by Brazilian and Argentine authors. The challenge was to extend this concept, a very plastic and multifaceted one, to a South American region that has not been visited by our historiography, aiming some new possibilities of understanding and research. While it is extremely difficult to approach populism in these States, some similarities and parallels may reinforce the relevance of the concept.
\end{abstract}

\section{Keywords}

Guiana. Suriname. French Guiana. Populism. Historiographic Balance. 


\section{Introdução}

Dentre tantas razões que podem ser apontadas para a escassa bibliografia brasileira sobre a História das Guianas, uma delas repousa na ausência de sincronismo histórico entre os demais fenômenos sociais e políticos do restante da América: período colonial, independências, Estado oligárquico, populismo, nacional-desenvolvimentismo, golpes militares e ditaduras, aberturas democráticas e neoliberalismo. Enquanto, de alguma forma, é possível comparar cada um desses elementos - ou todos eles - nos países americanos de colonização ibérica, ao recortar a história da Guiana, do Suriname e da Guiana Francesa a tarefa a princípio pode se apresentar anacrônica.

Não obstante, o fenômeno do populismo, tão multifacetado e plural, confere margem de reflexão para incluirmos o extremo norte do subcontinente também sob essa chave, com todas as diferenças e especificidades temporais e geográficas. Na República Cooperativa da Guiana (antiga Guiana Inglesa), ocorreu um formidável movimento de massas após a Segunda Guerra Mundial, derrotado com a intervenção anglo-americana no início dos anos 1960, fato que, por sua vez, formatou a independência política em 1966. Em 1970, Forbes Burnham, que governaria o país por dezenove anos ininterruptos, até sua morte em 1985, se fez "carismático" e decretou a instalação de uma República Cooperativa que levou o jovem país ao campo dos não-alinhados e promoveu articulações com Cuba e com o Leste europeu. Como tentarei explorar neste artigo, de socialismo havia muito pouco ali, sobressaindo práticas políticas que poderíamos enquadrar no conceito de populismo.

O Suriname, país de colonização holandesa, igualmente protagonizou um período significativo de lutas políticas a partir de 1945, com a formação de sindicatos universalistas, admitindo trabalhadores de todos os credos e etnias, e partidos políticos que, pelo contrário, foram marcados pela afiliação religiosa, numa interessante inversão entre o que seria o lugar do interesse corporativo e o do interesse geral. Conquistou sua independência em novembro de 1975, mas logo sucumbiu a um golpe militar em fevereiro de 1980, que progressivamente foi direcionando a jovem nação para o campo socialista. Reforçando a figura da liderança, o Estado surinamês decretou-se "revolucionário", estreitando relações com movimentos de esquerda e com as nações do bloco soviético, com predomínio dos cubanos. Ao abandonar essa diretriz em fins de 1983, ao preço de manutenção no poder do mesmo grupo político/militar de então, o Suriname sugeriria possibilidades de análises através da perspectiva conceitual em questão, com destaque para as expressões de "manipulação" e "aliança nova elite/massa" para concretização de um Estado nacional burguês articulado com o mercado mundial.

Muito embora a Guiana Francesa seja um caso totalmente à parte, na medida em que jamais se declarou independente, antes se tornou progressivamente incluída no Estado francês, hoje juridicamente uma Coletividade Francesa de Ultramar (CTOM - Collectivité Territoriale d'Outremer) - é possível, também nesse caso, extrapolar o conceito de populismo buscando, mesmo num Estado não soberano, manifestações que ajudem a enriquecer o conceito e, pari passu, ser explicado parcialmente por ele. De resto, uma tentativa já iniciada com bastante qualidade e pertinência por Stéphane Granger (GRANGER, 2016: 158-178).

Como bem afirmou o historiador Fernando Perlatto, o debate sobre o populismo talvez tenha sido o qual "mais se gastou página nas ciências sociais e na historiografia brasileira ao longo das últimas décadas" (PERLATTO, 2016: 70). Ou, de acordo com Ângela de Castro Gomes, "um conceito com um dos mais altos graus de compartilhamento, plasticidade e solidificação" (GOMES, 2001: 20). Para os argentinos María Moira Mackinnon e Mario Alberto Petrone, um conceito que resiste a ser aposentado, "se obstina a perdurar, ronda a linguagem cotidiana, assoma com frequência os trabalhos acadêmicos" (MACKINNON e PETRONE, 1998: 14).

Nesse sentido, o texto que se segue se configura mais como exercício epistemológico do que necessariamente novidades historiográficas. A região em apreço possui peculiaridades acentuadas no que tange ao sistema político, cultura, geografia e desenvolvimento econômico, de sorte que uma narrativa a partir do conceito de populismo, embora tão rico e plural, reclama extremo cuidado e uma série inumerável de ressalvas. Nas entidades em tela, Guiana, Suriname e Guiana Francesa, nunca se concretizou um processo de industrialização, tampouco o problema de inserção no Estado oligárquico (independente) de uma numerosa e estendida classe trabalhadora em formação. O carisma da liderança, embora sempre tentada, ficou a muitas léguas de distância dos congêneres de outros lugares. 
Os setores populares estiveram atravessados por fortes divisões étnicas, com línguas e costumes extremamente distintas. A independência política e o grau de autonomia econômica, fatores centrais na experiência populista, foram vetores deveras truncado e tardios. Mesmo assim, acredito que práticas populistas se ensaiaram em momentos decisivos da história desses territórios, e até regimes populistas foram configurados em ocasiões curtas. Partido populista é o que talvez esteja completamente ausente, como espero demonstrar no decorrer do texto.

O método de exposição empregada foi a articulação entre certa bibliografia histórica, que analisa as Guianas na perspectiva de longa duração, e algumas obras de referência sobre a teoria e a prática populista na América latina, rearranjando contextos e análises utilizadas para outras ocasiões.

A inserção de uma história mais recuada respondeu a necessidade de situar a formação desses Estados no decorrer do século XX, de modo a fornecer melhor circunscrição nos períodos em que os acontecimentos se aceleraram e a possibilidade de pensar quando o populismo se fez presente.

\section{O Processo Político na Guiana e o Populismo}

Encravada na América do Sul mas com influência caribenha, a história política da Guiana guarda semelhanças com as ilhas de colonização britânica, como a Jamaica e Trinidad e Tobago. No início do século XX a configuração da classe trabalhadora ganhou contornos mais nítidos, com o término da imigração em massa de trabalhadores asiáticos - cerca de 270 mil, mais alguns milhares de chineses e portugueses - que foram importados para substituir os negros escravizados.

Os imigrantes asiáticos tenderam a se instalar na zona rural, formando a maioria da mão de obra envolvida na manufatura do açúcar. Os portugueses e chineses se apegaram ao comércio varejista, enquanto os afro-guianenses se basearam grosso modo nas cidades, nos serviços braçais ligados a construção e a estiva, mas também em outras profissões como advogados, professores e funcionários públicos de baixo escalão, de maneira a configurar o espectro da classe trabalhadora guianesa. Com a Inglaterra dedicando-se às colônias da África e da Ásia, os súditos sul-americanos sentiam-se bastante negligenciados, com seus problemas agravados pela falta de amparo da metrópole.

Consolidou-se no pós-Primeira Guerra Mundial a liderança de Hubert Nathaniel Critchlow, afro-guianense e estivador. Em janeiro de 1919, com centenas de outros trabalhadores, fundou a "União dos Trabalhadores da Guiana Inglesa" (British Guiana Labour Union - BGLU). Nesse final desse mesmo ano a Associação já contava com 13 mil membros e um saldo financeiro de quase 10 mil dólares guianenses depositados em banco:

Embora com forte apoio dentre os trabalhadores da estiva de Georgetown, era uma união geral, representando todos os trabalhadores independente de ocupação, localização ou raça. Além dos trabalhadores da estiva, seus membros incluíam porteiros, comerciantes, trabalhadores de estrada, empregados das estradas de ferro e alguns cortadores de cana (WOOFORD, 2009: 281).

Uma das primeiras conquistas foi a abolição do trabalho noturno e de domingo dos padeiros. E, uma das mais importantes, a legalização de toda atividade sindical, decretada em junho de 1921 depois de pressão inclusive do Partido Trabalhista Inglês. Com isso, a "União dos Trabalhadores da Guiana Inglesa" tornou-se a primeira instituição sindical de todo o mundo colonial britânico (WOOFORD, 2009: 284). Faz-se necessária uma pesquisa mais acurada a respeito da ligação entre o trabalhismo na metrópole e a situação na colônia, o que infelizmente não pôde ser levada a cabo diante da ausência de fontes disponíveis no momento.

Além da tradicional negociação salarial com os patrões, a União desenvolveu ao longo dos anos 1920 várias ações voltadas para os trabalhadores precários ou desempregados, como alimentação coletiva e outras atividades assistencialistas. A importância de todas essas iniciativas extrapolou o âmbito local e reverberou no entorno regional. Em 1926, a Guiana Inglesa sediou o primeiro "Congresso dos Trabalhadores das Índias Ocidentais", com participação de líderes sindicais de várias colônias inglesas do Caribe.

Durante a segunda metade daquela década, Critchlow participou de encontros em Londres com líderes sindicais da metrópole, ainda representando a Guiana Inglesa em dois importantes 
eventos no ano de 1931: o "Comitê Internacional dos Sindicatos dos Trabalhadores Negros", na Alemanha de Weimar, e a "Ajuda Internacional Vermelha", na União Soviética.

Por outro lado, a depressão que o mundo capitalista enfrentou nos anos 1930, com impactos diretos no império colonial inglês, apresentou desafios de monta que acabaram dificultando o crescimento dessa União. O desemprego afetou materialmente a associação, e o aumento da repressão governamental acabou selando a sorte de Critchlow. O desgaste de sua longa liderança, somado às limitações oriundas das profundas, e nem sempre simples de serem ultrapassadas, divisões étnicas foi minando seu prestígio junto à população trabalhadora. 0 estatuto colonial da Guiana Inglesa igualmente prejudicou a sustentação prolongada.

Outras instituições acabaram ocupando os espaços, como a Liga dos Trabalhadores da Guiana Inglesa (British Guiana Workers League), fundada em 1931, e a Associação dos Cidadãos Trabalhadores (Manpower Citizens's Association) de 1937. Durante a Segunda Guerra Mundial e após, o movimento dos trabalhadores daria um salto significativo, com o fortalecimento e a união de antigos e novos sindicatos.

Nesse sentido, plasmou-se um forte partido marxista de inspiração leninista, o PPP (People's Progressive Party), que amalgamou tanto os descendentes de indianos quanto os afro-guianenses, as duas principais etnias. Nos anos 1950, sob a liderança de Cheddi Jagan, o partido foi conquistando as eleições legislativas, forçando uma posição defensiva dos governadores coloniais e mesmo uma intervenção de tropas britânicas para dispersar o movimento. Jagan se declarava simpatizante da URSS, sua esposa detinha conhecido passado de militância no Partido Comunista dos Estados Unidos. A partir de 1960, o afinamento ideológico com Cuba, e seu próprio crescimento interno, precipitou uma ingerência norte-americana, através do financiamento de opositores e do incitamento de divisões interétnicas, o que levou o PPP ao racha e fortaleceu o PNC (People's National Congress), este último ainda inspirado em algumas referências socialistas, mas em nome da supremacia dos negros (RABE, 2005).

Em acordo com a Inglaterra, o sistema eleitoral foi alterado em 1962, o que permitiu a vitória de Forbes Burnham, líder do PNC, e a repressão aos partidários do PPP. Com apoio anglonorte-americano, Burnham liderou a independência, conduzindo um governo repressivo internamente que se manteve através de fraudes eleitorais, seguindo com apoio externo de Londres e Washington. O movimento popular não foi desarticulado, antes permaneceu numa postura de certa euforia com a independência e, posteriormente, de espera e decepção, à medida que 0 atraso econômico e as dificuldades sociais recrudesceram. Com a falta de democratização do poder político, uma elite local se consolidou, garantindo apoio na minoria abastada ao governo, mas insuficiente para incorporação de grandes parcelas da população.

Em 23 de fevereiro de 1970, Burnham rebelou-se contra os antigos aliados, declarando um programa de estatizações e um novo posicionamento internacional, em direção da construção de uma economia antagônica ao mercado. Nasceu a "República Cooperativa da Guiana", estabelecendo como razão de ser o 'socialismo cooperativo', uma forma tida como superior de divisão social do trabalho.

Essa atitude decorreu de respostas encontradas em relação às contradições externas e internas. No primeiro caso, a ausência de investimentos mais robustos na economia guianesa por parte de Inglaterra e Estados Unidos levou Burnham a endurecer sua postura na política externa. Decepcionado com a falta de um programa de apoio econômico anglo-americano, esperado após o papel desempenhado na independência, talvez o líder guianês tenha imaginado que a retomada do ideário socialista, sobretudo na esfera do discurso, fosse uma maneira de barganhar atenção dessas economias centrais.

Por outro lado, internamente, as aspirações de setores das classes trabalhadoras seguiram na perspectiva socialista, impelindo Burnham a assumir tal compromisso na configuração de sua política de Estado, de modo a conservar legitimidade.

Aqui já se arrisca a primeira aproximação com um regime populista, ou seja, na medida em que a classe trabalhadora guianesa, forjada ideologicamente sob influência do trabalhismo inglês e posteriormente do socialismo do PPP, pouco se reconheceu no governo nascido com a independência, que acabou por incorporar aspirações genuínas de classe num sentido muito mais retórico do que prático. Embora estivesse em jogo a supremacia dos negros sobre os indianos, traço jamais presente em outros populismos sul-americanos, há certa similitude, com o Estado encampando símbolos e palavras de ordem populares, passando posteriormente ao partido a supremacia e o comando ao líder que era "capaz de mobilizar as massas e empolgar o poder" (GOMES, 2001: 25). 
No bojo do processo Burnham decretou a "supremacia do partido sobre o Estado", algo assemelhado ao peronismo argentino, fazendo do seu movimento o único e legítimo de toda nação. Na oposição estariam colocados interesses "antinacionais" pura e simplesmente.

Na visão de Ângela de Castro Gomes alguns elementos em comum perpassaram as diversas experiências históricas populistas:

um proletariado sem consciência de classe; uma classe dirigente em crise de hegemonia; e um líder carismático, cujo apelo subordina instituições (como partido, embora com ele conviva) e transcende fronteiras sociais (de classe e entre os meios urbano / rural) (GOMES, 2001: 25-26).

Pode-se afirmar que a consciência de classe não estava ausente nas classes subalternas da Guiana, formada basicamente por cortadores de cana, empregados de empresas mineradoras, trabalhadores da estiva e profissionais liberais, como professores e comerciários, mas sim embaralhadas nas questões étnicas, na medida em que o partido do governo, o PNC, declarava abertamente política favorável a população negra, excluindo indianos, javaneses e chineses. A crise de hegemonia se apresentava nesse desafio de construção do Estado independente, num contexto de reestruturação econômica internacional e baixas taxas de crescimento interno.

Na chamada "Declaração de Sophia", em 1974, Burnham, sintetizou as metas:

a) garantir que o povo da Guiana seja dono e controle em seu benefício os recursos naturais do país; $b$ ) a transferência do poder econômico para as massas; c) o fim da pobreza e a construção de uma sociedade próspera; d) o fim da exploração e a construção de uma sociedade igualitária, justa e sem classes; e) produção para as necessidades humanas no lugar de produção para o lucro (BURNHAM, 1974: 9-31).

A série de nacionalizações levada a cabo entre 1970 e 1976 acabou fortalecendo tanto a classe dos pequenos capitalistas guianenses quanto a burocracia de Estado. Esta tornou-se beneficiária do crescimento estatal, alguns tornando-se mesmo empreendedores, enquanto que os primeiros confiaram na capacidade do regime em controlar os descontentamentos dos trabalhadores através do reforço da supremacia de raça.

Em verdade, o Estado contribuía para a cristalização de uma elite local através do controle sobre os meios de produção, sendo então galvanizado pela mesma elite no sentido de legitimidade e apoio: "Nesta formulação, fica muito claro que o compromisso/apelo às massas - segmentos urbanos em geral - é um recurso para encontrar suporte e legitimidade em situação de crise de instabilidade, de incerteza política" (GOMES, 2001: 33).

Essa crise de legitimidade interna, somada a crise econômica internacional, levava o governo a reiteradamente manter um nível de mobilização de sua população. $O$ boicote dos países Ocidentais, liderados pelos Estados Unidos, fechou o essencial caminho do aporte externo de capitais para um país pequeno e subdesenvolvido, potencializando o atraso e a deterioração do nível de vida das classes subalternas e da classe média, essa última sobremaneira diminuta nessa complexa engenharia social.

Os números da economia nesse período decresceram. O PIB diminuiu, o desemprego e a inflação multiplicaram, a desindustrialização e a perda de produtividade da agricultura atingiram picos históricos. A carestia castigou o povo guianense, com aumento do custo de vida e diminuição dos salários. Eletricidade, combustíveis, sabonetes e mesmo água foram racionados, por conta da deterioração da capacidade econômica do Estado (CHANDISINGH, 1983: 67). As duas maiores empresas multinacionais, a Companhia de Bauxita de Demerara, pertencente a ALCOA do Canadá, e a Booker MacConell, pertencente aos britânicos, foram nacionalizadas. Respectivamente, eram produtoras e exportadoras de bauxita e de açúcar. Em 1976, o Estado era responsável por $80 \%$ de toda economia, com $10 \%$ nas mãos da iniciativa privada e outros $10 \%$ em cooperativas. Entre 1980 e 1987, o declínio da economia guianesa - recuo de mais de $6 \%$ - só não foi pior que a da Líbia, Moçambique e Catar" (BOTHERSON JR, 1989: 10).

De acordo com Steve Garner, os indicativos econômicos para 1986 apontaram que o PIB havia regredido para o mesmo patamar de 1970, enquanto a dívida externa havia saltado três vezes e meia nesse intervalo. A população encolheu $1 \%$ e a ajuda humanitária foi enviada de países como a Iugoslávia e o Canadá. A taxa de homicídios na segunda metade dos anos 1980 ficou apenas atrás do Líbano (GARNER, 2008: 177). 
Regionalmente, a República Cooperativa da Guiana logrou grande influência do Mercado Comum do Caribe (CARICOM), sendo sede da instituição até os dias atuais. As negociações coletivas do bloco foram amiúde conduzidas por Burnham, tais como em relação a Comunidade Econômica Europeia e a África. Em relação a essa última, o líder guianês exprimiu uma diuturna crítica ao regime de Apartheid na África do Sul (CAVLAK, 2016a).

Obviamente essas posições não foram desenvolvidas sem uma reação estadunidense, que boicotou e restringiu o comércio exterior da Guiana, embora com cuidados para que, caso Burnham caísse, não o substituísse os marxistas do PPP. Uma espécie de cordão sanitário internacional pairou sob a nação. Em 1947, com seu movimento em extrema ascensão na Argentina, Juan Domingo Perón decretou uma "Terceira Posição", identificando seu país como desapegado tanto do bloco liderado pelos Estados Unidos quanto da União Soviética. Uma necessidade de mesclar afirmações de políticas nacionalistas com a impossibilidade mesma de seguir uma aliança total com as grandes potências. No segundo governo Vargas, de 1951 até 1954, também muitos foram os atritos com Washington, alimentando com isso uma oposição interna articulada aos norte-americanos, que ao fim e ao cabo inviabilizaram o governo central. No México de Lázaro Cárdenas, durante a segunda metade dos anos 1930, também o relacionamento com os EUA chegou as vias da ruptura, sobretudo em 1938, com a estatização do petróleo. Isto é, nos populismos ditos clássicos, também um elemento de desacordo com a potência hegemônica foi constante.

Tomando uma definição de José Luís Romero, segundo o argumento de Alberto Aggio, pode-se afirmar que o populismo seria "um movimento de direita paradoxalmente voltado para a esquerda" (AGGIO, 2003: 145). Teríamos assim, na Guiana, uma espécie de movimento direitista encampado, no campo do discurso, por símbolos e referenciais de esquerda, levando inclusive a um posicionamento internacional, de caráter prático, no campo de nações terceiro-mundistas e marxistas-leninistas.

\section{O Processo Político no Suriname e o Populismo}

O Suriname, colônia holandesa encravada na América do Sul, também padeceu de relativo déficit de atendimento da sua metrópole até a primeira metade do século XX. As possessões na Antilhas, como Curaçao e Aruba, mas sobretudo as colônias na Ásia, como a Indonésia, drenavam muito mais recurso e energia de Amsterdã. Com a abolição da escravidão negra nos anos de 1860 , várias levas de imigrantes contratados desembarcaram em Paramaribo, oriundas da própria Indonésia, Java, Índia e China. De forma quiçá mais acentuada que a vizinha Guiana, o Suriname consolidou população trabalhadora ainda mais fragmentada do ponto de vista étnico/cultural.

Uma especificidade nesse sentido foi a formação, desde o século XVII, de comunidades de negros fugidos da escravidão no interior da colônia. Conhecidos como marrons ou bush negroes, estabeleceram acordos com as autoridades holandesas e puderam permanecer enquanto sociedades apartadas e protegidas da ocidentalização econômica e cultural. De sorte que, até os dias atuais, formam um importante seguimento da população global do Suriname, espécie de "Estado dentro do Estado" possuindo leis e formas administrativas autônomas.

Nos anos de 1930, a momentânea desarticulação comercial fruto da crise contribuiu para rotatividade da mão de obra, levando muitos trabalhadores das cidades, sobretudo afrosurinameses, a buscarem trabalho nas ilhas do Caribe. Entre idas e vindas, surgiram lideranças articuladas ao ideário comunista e socialista, sendo a de maior destaque a de Anton de Kom, além de mineiro, um grande intelectual. Em 1932, foi fundada a "Organização dos Trabalhadores Surinameses", desarticulada com a repressão violenta do governo e a prisão e posterior deportação de Kom (CAVLAK, 2016b: 69).

Mesmo após o final da Segunda Guerra Mundial, a exploração de bauxita continuou como produto principal. Assim, o novo arranjo político foi a administração colonial passar para as mãos da acanhada elite local, enquanto a economia continuava sendo comandada da Holanda. Os planos de desenvolvimento que se seguiram contaram com empréstimos e financiamentos metropolitanos, como o plano de dez anos (1955-1964), os planos complementares de 1962 e 1965 e os planos quinquenais de 1967-1971 e 1972-1976 (CAVLAK, 2016 b: 70).

Nesse tempo foram surgindo os partidos políticos: Moeslim Partjd (Partido Muçulmano), Protestant Nationale Partij Suriname (Partido Nacional do Suriname, baseado no movimento evangélico), Roman Catholic Progressieve Surinaamse Volkspartij (Partido Popular Progressista do Suriname, baseado no catolicismo), Verenigde Hindostaanse Partij (Partido Unido dos Hindus) e o Kaum Tani Persatuan Indonesia (União dos Camponeses Indonésios). Como todos os nomes 
indicam, eram partidos centrados mais na nacionalidade e religião e menos em ideários puramente políticos (HOEFTE, 2014: 100).

Um reflexo das condições sociais locais, essa forma de partido era mais tolerada pela administração holandesa, na medida em que a união classista aumentaria o poder de barganha dos trabalhadores da colônia. Essa forma de se fazer política fortaleceu o clientelismo e a divisão racial, pois cada grupo se comprometia a melhorar a vida dos adeptos de sua religião e etnia, negligenciando a noção de espaço público e demandas universais. Acesso aos direitos, cargos e bem-estar estavam condicionados a lealdade em detrimento da generalização das demandas. "Coalizões não eram baseadas em plataformas políticas compatíveis, mas em oportunistas e pragmáticas considerações para ganhar poder" (HOEFTE, 2014: 100).

As incertezas que a economia mundial apresentou no final dos anos 1960 e início dos anos 1970 reverberaram no Suriname. Várias greves e manifestações se fizeram presente, confirmando a maior tendência de radicalidade dos sindicatos em relação aos partidos. Naquele momento, a população totalizava pouco mais de 379 mil indivíduos, sendo 148 mil hindus, 118 mil afrosurinameses, 58 mil javaneses, 39 mil quilombolas e 10 mil ameríndios (HOEFTE, 2014: 108).

Em outubro de 1975, o parlamento holandês, mesmo recebendo pressão do Partido Hindu do Suriname para atrasar o processo, votou a favor da separação. Foram 106 votos a favor contra 5 entre os deputados e 53 a favor contra 11 entre os senadores metropolitanos. Se havia muitas dúvidas em Paramaribo sobre a separação, em Amsterdã a certeza era de que não convinha mais manter formalmente uma colônia problemática, em razão do desgaste tanto político quanto econômico (CAVLAK, 2016b: 75).

Após 25 de novembro de 1975, quando oficialmente surgiu uma nova nação, a situação não mudou substancialmente. Em se tratando de uma economia deficitária, uma sociedade pobre, sem grandes ligações com o restante da América do Sul, a Holanda continuou sendo a grande referência. O sistema político se configurou enquanto amálgama de referências holandesas e surinamesas. Como explica Urt, citando MacDonald:

$$
\begin{aligned}
& \text { O sistema político que existiu no Suriname entre } 1975 \text { e } 1980 \text { combinava } \\
& \text { diversas características. Foi constituído como uma democracia parlamentar } \\
& \text { de inspiração ocidental, mas combinava características do apanjaht e da } \\
& \text { democracia consorcional. O apanjaht era o sistema de partidos com } \\
& \text { identificação étnica e correspondente disposição popular de votar por sua } \\
& \text { própria raça. Os principais partidos políticos do Suriname eram ligados aos } \\
& \text { crioulos, hindustanis e javaneses, grupos étnicos que juntos detinham } \\
& \text { quase } 80 \% \text { dos votos. A democracia consorcional, por sua vez, importada } \\
& \text { dos Países Baixos, consistia numa forma de governo em que as divisões } \\
& \text { étnicas eram apaziguadas por meio de sistemas de proporcionalidade e } \\
& \text { compartilhamento de poder (URT, 2010: 71). }
\end{aligned}
$$

Com o andamento da crise mundial, os descontentamentos foram potencializados, até que, em fevereiro de 1980, jovens oficiais do então recém-criado exército tomaram o poder através de um golpe militar, liderado por Desi Bouterse. A consigna maior era o combate a corrupção e a velha política, uma projeção na consciência social desse grupo da insuficiência de um Estado-nação minimamente consolidado e com identidade assertiva. Para João Nackle Urt, tratou-se de um golpe "atípico", voltado para questões estritamente militares, tanto que o presidente Ferrier foi mantido no posto, embora os partidos tradicionais representantes das etnias fossem retirados da administração: A "rebelião dos sargentos", como ficou conhecido o episódio, foi um golpe militar atípico. Não tinha caráter revolucionário, nem reacionário. Não partiu de preocupações relacionadas a Guerra Fria. Não seguiu a lógica das doutrinas de segurança inspiradas nos Estados Unidos, nem de alinhamentos a União Soviética. Foi um levante militar provocado por questões exclusivamente internas, quase que limitadas ao espectro das relações da classe militar com o governo (URT, 2010: 71).

Podemos relacionar essa aparente falta de coloração do golpe a uma crise de representatividade no sentido de "vazio político" oriundo da transição entre um Estado oligárquico para a democracia burguesa, identificando aqui o período colonial com o primeiro e o período de autonomia com o segundo. Analisando a situação do Brasil no período da Revolução de 1930, comenta Aggio: 
Uma vez que os antigos grupos oligárquicos haviam sido deslocados do poder de Estado, sem que nenhuma classe social demonstrasse capacidade hegemônica para assumir integralmente seu controle, as massas populares apareceram, nesse contexto, como único segmento social capaz de garantir legitimidade ao novo Estado que emergira (AGGIO, 2003: 152).

Se, por um lado, no caso em tela, não houve ruptura entre a elite política colonial e a elite política do novo país, por outro lado, a invenção da nação reclamou mudanças na organização social, até para justificar a nova entidade política descolonizada. Mesmo tendo em conta que em 1970 o mundo já estava industrializado, e no Suriname não ocorreu uma "passagem da sociedade rural para a urbana", não era tão simples o emergir de uma nacionalidade de maneira oficial sem um rearranjo em alianças de classes e o regime político antigo de representatividade. Daí, a meu juízo, o avanço popular dos militares em busca da classe trabalhadora organizada para, em contrapartida a oligarquia colonial - que seguiu dando as cartas nos primeiros anos da nação -, se legitimar enquanto ator reconhecido e enraizado no sistema de poder.

Numa análise mais sofisticada, pode-se relacionar o seguinte raciocínio sobre o populismo:

A transição de uma mentalidade tradicional forjada numa matriz autoritária e paternalista a uma moderna baseada em indivíduos autônomos e livres produz um estado de anomia frente a falta de canais institucionais adequados. Saídos da mentalidade tradicional mas ainda incapaz de levar a cabo nenhuma ação coletiva autônoma, estas massas são vistas como potencialmente explosivas. A rigidez do sistema político e a incapacidade dos atores políticos de dirigir a crise favorece a emergência de uma figura carismática, que junto com elites diferentes os recruta e manipula. Este líder populista logra criar vínculos poderosos e diretos com essas massas disponíveis - como apoio eleitoral - mas também logra atrair os novos setores modernizantes como o exército e os industriais (MACKINNON e PETRONE, 1998: 26).

Como em outros países, a fragilidade da classe trabalhadora e suas organizações, símbolos e meios de difusão, se mostrou um limitador para a configuração de um projeto autônomo de poder com possibilidade de hegemonia. A classe trabalhadora surinamesa tornar-se-ia elemento chave da nova coalização, embora de maneira subalternizada. Na crise que se desdobrou na segunda metade dos anos 1970, não aceitava mais o sistema de apanjaht/consorcional, insatisfação captada e absorvida pelas lideranças do jovem exército.

Um segundo momento do golpe, em agosto de 1980, depôs o presidente Ferrier e potencializou o poder de Bouterse, embora outro presidente tenha sido escolhido para a chefia de Estado, Chin A Sen. A aliança com os partidos de esquerda se fortaleceu, amalgamando-se num duplo poder entre militares e classe trabalhadora organizada. Para Avila, naquele contexto:

A rejeição dos militares aos denominados partidos de orientação étnica especialmente ao Partido Nacional do Suriname e ao Partido da Reforma Progressista - resultou na convergência com dois pequenos partidos de esquerda: a União Progressista dos Trabalhadores Pobres (Progressieve Arbeiders en Landbouwers Unie - PALU, de orientação nacionalista e dirigido por Errol Alibux e Winston Caldeira) e o Partido Revolucionário do Povo (Revolutionaire Volkspartij - RVP, de orientação castrista e dirigido por Michael Naarendorp). Gradualmente, os militantes do PALU e do RVP assumiram importantes cargos ministeriais no governo revolucionário (AVILA, 2011: 9).

O parlamento foi fechado e a Constituição suspensa.

A meu juízo, teríamos uma situação semelhante ao interregno na vizinha Guiana, entre a independência em 1966 e a declaração da República Cooperativa em 1970. Na necessidade de inventar a nação, de legitimar uma nova classe dirigente numa conjuntura de crise, envereda-se para articulações com as classes subalternas, sem necessariamente significar uma mudança radical na gestão dos meios de produção. Uma elite que governa com apoio popular e, de modo a não deixar escapar esse controle, lança mão de instrumentos autoritários que distancia o regime de uma democracia liberal. 
Comentando algumas teses de Francisco Weffort, os autores argentinos María Moira Mackinnon e Mario Alberto Petrone escrevem que práticas populistas se articulam com "a formação de uma burguesia urbana e intensificação do desenvolvimento industrial, expansão do sindicalismo e liderança do comportamento trabalhista", dentro de uma capacidade de conciliar aspectos contraditórios de Estados modernos numa sociedade capitalista. Como se "usurpassem" pautas socialistas e liberais e as fundissem no mesmo regime (MACKINNON e PETRONE, 1998: 15-16).

A partir de então, o regime foi se transmudando para identificações e alianças internacionais com o bloco socialista, um desafio para a Holanda e sobretudo para os Estados Unidos. A experiência socialista de Maurice Bishop em Granada tornou-se espelho e ponto de apoio. Em maio de 1981, o governo lançou o "Manifesto da Revolução", potencializando a política de alianças entre a casta militar e partidos de esquerda como a "União dos Trabalhadores das Fazendas e Trabalhadores da Cidade". Tratava-se de organizações plasmadas ainda no período colonial, minoritárias até então, mas com formação de quadros e um conjunto de ideias organizado. Aspirações nacionalistas se amalgamavam com o ideário autonomista e de crítica a economia de mercado, além das aspirações pela nacionalização da economia e expropriação das grandes fortunas (CAVLAK, 2016b: 80).

Embora o governo não se sentisse inclinado em tomar essas atitudes internas, externamente a projeção foi marcante. As relações diplomáticas com Havana cresceram de maneira vertiginosa, com a chegada de técnicos, organizadores políticos e médicos da ilha. No final de 1981, aboliu-se a necessidade de visto para que cidadãos cubanos entrassem no Suriname. Na inauguração do chamado "Gabinete Revolucionário", ainda nesse ano, participaram importantes delegações da Nicarágua, Granada e revolucionários da Frente "Farabundo Marti para a Libertação Nacional" de El Salvador além, obviamente, do pessoal diplomático cubano (CAVLAK, 2016b: 81).

Em 4 de fevereiro de 1982, Chin A Sen foi afastado do poder, aparentemente por representar um grupo político que assumira a bandeira da democratização política, com a volta dos parlamentares, Constituição e, sobretudo, eleições. O presidente reverberava a oposição ao que se entendia como um excessivo apreço aos cubanos e ao ideário socialista. Nesse sentido, um golpe de direita, em apoio ao presidente deposto, tentou a derrubada de Bouterse que, rapidamente, contando com apoio popular, desarticulou os adversários e conseguiu se manter no poder:

O segundo golpe partiu de um grupo de dissidentes da rebelião dos sargentos, insatisfeitos com os rumos que o pais vinha tomando, sobretudo com a orientação socialista e neutralista imposta por Bouterse. No dia 11 de março de 1982, oficiais direitistas chefiados pelos tenentes Surendre Rambocus e Henri Gorre e pelo sargento-major Wilfred Hawker anunciaram ter deposto o governo esquerdista do Suriname. Mas o presidente conseguiu escapar e reuniu suas forças nos arredores da capital, preparando uma contra-ofensiva eficaz (URT, 2010: 73).

Em três dias, os golpistas foram presos e Wilfred Hawker fuzilado.

Esse exemplo pode ser tomado como a contrapartida popular ao regime, ou seja, mesmo que outras forças esposassem a bandeira das liberdades civis e da economia de mercado, não assinalavam para maior participação popular, o que estava na pauta do comandante Bouterse, ainda que de forma dependente. Argumenta Aggio que:

Quando as massas irromperam na cena latino-americana nas primeiras décadas do século XX, as instituições políticas estruturadas pelo liberalismo demonstraram toda sua insuficiência no sentido de acomodarem conflitos e promoverem a integração social e política (AGGIO, 2003: 140).

Ou seja, na medida em que a independência no Suriname é tardia, também o é a questão da incorporação de uma democracia ampliada, que o sistema misto de representação surinamês/holandês não deu conta de prover, sendo a configuração assumida progressivamente a partir de 1980 uma resposta para esse desafio.

Em maio de 1982 Bouterse participou da Conferência Internacional Socialista, ocorrida em Granada, e posteriormente negociou com Fidel Castro em Havana. Buscando um outro polo desse campo, enviou representantes a Moscou, redundando na abertura da Embaixada soviética em Paramaribo. Na variável externa, assim como tantas outras experiências populistas, a exigência de desafio a hegemonia da potência regional e a procura de novos parceiros e referências ideológicas. 
Em outubro Bishop esteve em Paramaribo, sugerindo a construção de um arco de alianças cada vez mais evidente na direção de reformas econômicas socializantes, com o aval internacional de nações opositoras aos Estados Unidos e ao sistema internacional do Ocidente, tal como configurado nessa última fase da Guerra Fria. Essa visita desencadeou uma série de manifestações, impulsionando tanto os defensores do aprofundamento da identidade socialista quanto dos contrários, aumentando a fervura da luta de classes:

Na ocasião, em comício paralelo ao organizado pelo governo, o líder sindicalista Cyril Dahl criticou duramente as tendências autoritárias predominantes no Suriname e exigiu a realização imediata de eleições, o retorno dos militares aos quartéis, o fim do estado de emergência e das detenções arbitrárias, a elaboração de uma nova lei de partidos políticos, o fim da censura e o respeito aos direitos humanos dos surinamenses. As demandas do líder sindical tiveram ressonância na sociedade particularmente nos setores liberais, nas classes médias e nos profissionais. Nos primeiros dias de novembro iniciaram-se negociações entre militares moderados encabeçados pelo major Roy Horb - segundo homem do regime - e a denominada Associação pela Democracia (AVILA, 2011:9).

Bouterse esgrimiu uma preferência pela "democracia popular", no lugar de uma "democracia parlamentar", como caracterizou o regime anterior. Muito provavelmente influenciado pelo desenvolvimento positivo que Bishop e o chamado New Jew Movement realizavam naquele momento na ilha de Granada. No lugar de recuar e negociar, avançou para posições mais assertivas e violentas.

Falta ainda mais material para refinarmos essa fase da história do Suriname. Dito isso, uma especulação é que Bouterse também sofria a pressão dos seus aliados nas forças populares, de sorte a se ver na contingência de cada vez mais aprofundar o sentido de sua retórica e sua prática, mesmo para assombro de seus colaboradores mais próximos e das classes mais tradicionais da sociedade surinamesa.

No dia 9 de dezembro de 1982, Bouterse assumiu o "controle absoluto" do país, censurando a imprensa, decretando toque de recolher e cortando as comunicações com a comunidade internacional. Prendeu os principais representantes da oposição, entre estudantes, advogados, sindicalistas, jornalistas e mesmo militares, fuzilando sumariamente a todos, num total de 15 execuções. Junto desses, 36 outras personalidades que já se encontravam encarceradas foram também eliminadas, sob acusação de tentativa de fuga. Assim, o poder se consolidou na liderança autocrática (URT, 2010: 73).

Também foram destruídas as instalações físicas da principal central sindical do país - Moederbond - e várias emissoras de rádio e televisão, bem como as sedes de jornais oposicionistas. Para o embaixador brasileiro em Paramaribo, Nestor dos Santos Lima, tratou-se de um virtual golpe preventivo "para liquidar de um só golpe todos os líderes potenciais do país em todos os setores, decapitando, assim, por um tempo, qualquer veleidade de reação do país à progressiva cubanização do Suriname" (AVILA, 2011: 10).

O pesquisador Carlos Frederico Avila entende que, antes de ganhar mais adesões com esses acontecimentos, Bouterse acabou questionado pela "paroquial" sociedade surinamesa, na época com pouco menos de 400 mil habitantes assustados com um tipo de violência fora do comum (AVILA, 2011: 11).

A Holanda se posicionou de maneira absolutamente contrária ao ocorrido, declarando uma hostilidade aberta ao governo Bouterse. Congelou fundos de investimentos e boicotou o comércio exterior da ex-colônia, além dos veementes protestos na ONU. Os Estados Unidos se prepararam para também desembarcarem tropas no Suriname, inclusive com o beneplácito de Amsterdã.

A interpretação da conjuntura de acordo com as agências de notícias ligadas a URSS era oposta daquelas dos norte-americanos e holandeses:

Palavras de compreensão e alento para o governo de Bouterse foram publicadas e emitidas na imprensa soviética e cubana. Para as agências noticiosas TASS e Prensa Latina, os acontecimentos do Suriname eram resultado de uma estratégia defensiva de um governo progressista e 
revolucionário diante das atitudes contrarrevolucionárias dos setores privilegiados do país. Igualmente, voos noturnos com apoio militar cubano foram confirmados após o massacre de dezembro - sem esquecer a continuidade da cooperação militar cubana em termos de cursos de treinamento e segurança. Cumpre acrescentar, fundamentado nas fontes diplomáticas disponíveis no momento, que a embaixada cubana em Paramaribo, então dirigida pelo senhor Oscar Oswaldo Cárdenas - antigo chefe do Departamento do Caribe do Partido Comunista Cubano -, era particularmente ativa na época, contando com o apoio e a simpatia dos militantes do RVP e da ala esquerdista das forças armadas (Badresein Sital, Chas Mijnals, Stanley Joeman). Diante do crescente isolamento perante as potências ocidentais, a alternativa soviético-cubana se tornou plausível (AVILA, 2011: 12).

Com efeito, a ditadura brasileira, sob liderança de João Figueiredo, que obviamente monitorava o contexto, entrou em contato com os norte-americanos, se oferecendo para mediar o conflito de sorte a evitar a presença de soldados norte-americanos na floresta amazônica. Brasil e Suriname eram signatários do TCA (Tratado de Cooperação Amazônica), de 1978, além de acordos culturais, de cooperação técnica e científica e do Acordo Bilateral de Transporte Aéreo assinado em 1980.

O Ministro Saraiva Guerreiro organizou uma missão diplomática, capitaneada pelo General Danilo Venturini, que viajou ao Suriname em abril de 1983 com o intuito de desmanchar os acordos internacionais de Paramaribo com as nações socialistas e garantir a mudança de rumo do governo socialista. Em troca, levou a proposta de ajuda financeira, política e militar (BANDEIRA, 2003: 458).

Após muitas negociações, a diplomacia brasileira foi bem-sucedida. Numa reviravolta nada menos que espetacular, Bouterse abandonou a retórica esquerdista, expulsou os conselheiros cubanos e rompeu relações com Fidel Castro, jurando lealdade ao bloco Ocidental. No final de 1983, uma delegação do FMI desembarcou em Paramaribo, costurando empréstimos e investimentos em companhia da "Iniciativa para o Caribe", um pacote de auxílio financeiro da administração Reagan em troca da lealdade política e contrapartidas econômicas das nações da região.

Arguta na análise da realidade surinamesa, a Embaixada Brasileira em Paramaribo, em Telegrama Confidencial datado de 8 de fevereiro de 1983, adiantara a possibilidade de uma reviravolta política, acusando o caráter volúvel do líder surinamês:

(...) segundo avaliação generalizada, Bouterse não tem praticamente compromissos ideológicos e utilizará a esquerda na medida de suas ambições e para a consolidação de seu poder pessoal. Não hesitaria ele, também, caso necessário, em atingir duramente os setores de esquerda, sendo sempre possível, por outro lado, que esses setores tentem ultrapassá-lo (citado por AVILA, 2011: 10).

Espocaram-se várias greves de trabalhadores contrários a essa nova etapa do governo surinamês, com destaque para os mineiros da Suralco e da Billiton, empresas multinacionais que, embora ameaçadas no período anterior, não haviam sido desapropriadas. A revolta de setores das classes populares aliadas a Bouterse tem a ver com o que Ângela de Castro Gomes definiu a respeito da manipulação, essa faceta bastante explícita com a reviravolta do governo:

A manipulação populista não é, de maneira simplista, uma estratégia urdida por políticos espertos para enganar o povo ingênuo. É bem mais complexa, pois dotada de uma ambiguidade intrínseca: é tanto uma forma de controle sobre as massas, como uma forma de atendimento de suas reais demandas. Embora seja muito mais enfatizada a dimensão do "mascaramento" existente nesse atendimento, a política "populista" é avaliada também como um caminho de acesso e de reconhecimento dos interesses dos setores populares (GOMES, 1998: 546. Apud AGGIO, 2003: 157).

Uma situação que pode explicar o que viria depois, com um descontentamento generalizado que acabou sendo canalizado para uma guerra civil de extrema violência. 
O desfecho dessa conjuntura foi o incremento dos investimentos norte-americanos e de sua respectiva Embaixada que, junto com a brasileira, tornaram-se as mais importantes do país. As greves foram reprimidas e os acordos com o FMI não chegaram a se concretizar, tampouco eleições presidenciais, um compromisso firmado pelo líder surinamês com os brasileiros e norte-americanos que acabou não sendo levado a cabo.

A partir de 1986, um racha nas forças armadas surinamesas, incentivadas ao que tudo indica pela Holanda, na tentativa de afastar Bouterse, criou-se uma alternativa de poder no chamado Exército da Selva, sob comando de Ronnie Brunswijk, ex-guarda costa do presidente. Sem uma ideologia clara, o conflito descambou para uma guerra civil que sangrou a já combalida estrutura econômica, gerando a morte de centenas de combatentes e civis e a fuga de 10 mil surinameses para a vizinha Guiana Francesa, na condição de refugiados. Como assinalado por Gomes e Aggio, à derrota do populismo não se seguiu mais democracia, senão a retirada do pouco que se havia conquistado dentro das práticas populistas (AGGIO, 2003, p. 161). A guerra civil surinamesa mostrou ser uma falência da tentativa de integração popular via aliança com os jovens militares, onde ao menos uma réstia de divisão social da riqueza foi ensaiada, traída, é bem verdade, pelo mesmo líder que a havia insinuado.

\section{O Processo Político na Guiana Francesa e o Populismo}

Difícil estabelecer a discussão do populismo numa colônia que progressivamente foi se tornando uma França de fato, último território da América do Sul ainda não independente, até pela ausência de uma bibliografia de fôlego sobre a história contemporânea dessa região de ultramar da União Europeia. Até onde se sabe, o conceito foi aplicado sempre a países independentes. O que se tenta aqui, aliás como no texto em geral, são aproximações e apontamentos.

Igualmente como suas congêneres de colonização holandesa e inglesa, a Guiana Francesa teve sua história profundamente afetada a partir da Segunda Guerra Mundial. Em 1946, seu estatuto de colônia foi abolido pela França, sendo doravante enquadrada na categoria de Departamento de Ultramar. Programas estruturados para melhoria da qualidade de vida da população passaram a ser implementados, como campanhas de vacinação, construção de hospitais, moradias e melhoramentos na agricultura.

Também novos empregos no âmbito do Estado passaram a ser criados, com salários atraentes no sentido de fomentar a chegada de franceses nascidos na Europa. O famoso complexo penitenciário foi fechado e, a partir de 1964, implantada a base de lançamento de satélites europeu no munícipio de Kourou.

O geógrafo de formação e pesquisador da história da Guiana Francesa, o franco-guianense Stéphane Granger, intentou uma interessante análise desse objeto através da problemática que nos interessa: "Nacionalismo e Identidade na Guiana Francesa: Um Populismo?" (GRANGER, 2016: 158176). Até por se tratar de um trabalho pioneiro e de notória qualidade, desenvolverei esse tópico através de sua argumentação.

No título do artigo o autor coloca uma interrogação, de saída estabelecendo a lógica de especulação entre a pertinência da realidade histórica com o conceito. Localiza nos anos de 1920 a figura política de Jean Galmot, que se tornou prefeito de Caiena através de uma retórica que se assemelhava a práticas populistas, como promessas e diálogos diretamente com a população, sem a mediação de um partido político ou uma plataforma programática estruturada. Galmot era um branco nascido na França, ex-garimpeiro que utilizava do prestígio na colônia para ganhar espaço na metrópole.

Ao contrário de outras colônias, na Guiana Francesa uma elite organizada em torno da Loja Maçônica empunhou não um ideário independentista, mas de apego e ligação completa com a França metropolitana. A partir de 1945, foi ela que logrou seu intento de anexação, solapando o possível crescimento de um movimento popular de aspiração autonomista. Os motivos são vários, desde a ausência de uma população etnicamente distinta, invadidas em suas antigas organizações sociais, como nas colônias africanas e asiáticas, até um apego ideológico aos valores da civilização francesa, fomentados nas escolas e multiplicados pelas intensas campanhas nacionalistas relativas as guerras mundiais no século XX. Apenas 30 mil pessoas habitavam o lugar naquele momento.

Duas personalidades se destacaram então: Gaston Monnerville, do partido Radical Socialista, de centro esquerda, que acumulara os cargos de prefeito de Caiena e Deputado Federal em Paris, e Félix Eboué, "primeiro administrador colonial negro da França e que teve um papel decisivo na organização da França Livre junto com o general De Gaulle" (GRANGER, 2016: 160). Ambos na luta pela integração guianesa à França "de fato". 
Na segunda metade de 1940, Monnerville foi derrotado nas eleições legislativas pelo jornalista René Jadfard, "personalidade aventureira muito popular entre os jovens, ex-garimpeiro, ex-resistente na metrópole" (GRANGER, 2016: 161). Lideranças com respaldo popular, acabaram sendo eclipsados, o primeiro por ter se mudado em definitivo para a França, onde seria presidente do Senado por vinte anos, e o segundo por sucumbir a um trágico acidente aéreo. Uma terceira liderança veio à tona, o jornalista Justin Catayée, que rompeu com os socialistas franceses e fundou, em 1956, o Partido Socialista da Guiana (PSG), elegendo-se deputado federal dois anos depois com a plataforma de maior autonomia "dentro da República francesa". Resume Granger da seguinte forma:

$\mathrm{O}$ que tinha de populista nessas personalidades? Todos eram democratas e republicanos, isto é, favoráveis a pertença à República Francesa, a favor da democracia representativa parlamentarista, e se valiam dessa popularidade com contatos até frenéticos com o que se poderia chamar, sem nenhum sentido pejorativo, de "povão", petit peuple em francês. Insistiam nas suas origens humildes e seu passado de trabalhadores manuais em Caiena ou no interior e de resistentes na França, mas nunca impuseram como homens providenciais, nem praticaram um culto da personalidade (GRANGER, 2016: 163).

Interessante que o líder máximo da República naquele contexto, Charles de Gaulle, poderia ser inserido em algumas práticas típicas de caudilhos latino-americanos, como o fortalecimento do personalismo e da liderança suprapartidária. Não o foi talvez por estar vinculado a realidade europeia, em tese imune a esse tipo de situação.

Fato é que, passados esses anos 1950, onde Perón na Argentina e Vargas no Brasil haviam sido derrotados, antes deles Cárdenas no México, na Guiana Francesa também nova fase se abriu, com o encontro, a partir de 1964, de estudantes e trabalhadores franco-guianenses e franceses envolvidos na construção da Base Espacial de Kourou, e a mistura com a população das antigas colônias na África e Ásia:

O contato desses estudantes com o marxismo e os movimentos revolucionários ou terceiro-mundistas da metrópole, a tomada de consciência da situação de "dominado" e de "colonizado" fizeram evoluir a reivindicação autonomista, que tomou um aspecto nacionalista e até independentista que não tinha verdadeiramente até lá (GRANGER, 2016: 164).

Nem franceses, como os metropolitanos, nem caribenhos, como os martiniquenses e guadalupenses, valorizando a língua creole e as raízes africanas e indígenas. Emergiu daí dois novos atores, a União dos Estudantes Guianenses (UEG) e a União do Povo Guianense (UPG), um autêntico partido nacionalista. Ambos objetivavam "esclarecer" e "emancipar" o povo franco-guianense, uma linguagem inclusive muito próxima dos populistas russos do século XIX. Entretanto, pouco conseguiram de real apoio de massas, traduzindo a emancipação política a uma oblíqua "autonomia de gestão". Em 1962, surgiu a União dos Trabalhadores Guianenses (UTG), primeira central sindical do departamento. De orientação comunista, forjou a bandeira da Guiana Francesa com a estrela vermelha no centro, até hoje o símbolo oficial da coletividade, e hegemonizou o apoio da classe trabalhadora organizada.

Cresceu a repressão das autoridades francesas, ao passo que a UTG aumentou sua influência na sociedade guianense, se declarando, em 1973, a favor da independência total frente a administração em Paris. Um ano depois, jovens intelectuais marxistas fundaram o Movimento Guianense de Descolonização (MOGUYDE), causando inclusive sérias preocupações no regime militar brasileiro, que identificou "desestabilizações marxistas ou pró-castristas nas suas fronteiras amazônicas, com o regime cubano de Fidel Castro apoiando oficialmente os separatistas francoguianenses" (GRANGER, 2012). Animados pela independência da Guiana, em 1966, e do Suriname, em 1975, além do avanço do socialismo em Granada, El Salvador e Nicarágua, os militantes do PSG potencializaram sua militância a favor da independência, inclusive com atentados a prédios públicos em Caiena entre 1978 e 1979. A vitória na França do socialista François Mitterrand, contrariando a ofensiva neoliberal desenhada em outros países centrais como Estados Unidos, Inglaterra e Alemanha, trouxe à Guiana Francesa o fortalecimento de práticas autonomistas, concretizadas na reforma administrativa de 1982, que concedeu de fato uma série de mecanismos 
auto-gestionários ao departamento. Com isso, arrefeceu o sentimento de busca da independência através de ações violentas fora do parlamento.

Grosso modo, foram criados dois corpos políticos complementares, o Conselho Geral responsável pelos assuntos sociais -, e o Conselho Regional - incumbido do planejamento econômico e cooperação com regiões fronteiriças. "O PSG e a esquerda autonomista, que tinham apoiado François Mitterrand, aceitaram o desafio e o líder do PSG Georges Othily foi eleito presidente do Conselho Regional da Guiana Francesa, estatuto quase parecido a um governador brasileiro" (GRANGER, 2016: 168).

Essa nova configuração possibilitou ao executivo da Guiana Francesa fomentar o crescimento econômico, com a construção de pontes, escolas, rodovias e locais de práticas esportivas e culturais. Em 1991, Othily se encontrou com o primeiro governador do Amapá, Aníbal Barcelos, dando início a uma série de encontros e protocolos de integração (GRANGER, 2016: 168), sendo os mais famosos as conversações entre Jacques Chirac e Fernando Henrique Cardoso, em 1996, e Luís Inácio Lula da Silva e Nicolas Sarkozy em 2008.

Não obstante essa nova arquitetura política, muitos problemas envolvidos na questão da independência continuaram, como o baixo nível de desenvolvimento econômico, ausência de indústrias e hegemonia dos altos cargos administrativos pelo pessoal nascido na França. Em 1991, foi fundado o Movimento de Descolonização e Emancipação Social (MDES), articulado a UTG e que passou a participar das eleições departamentais. Granger qualificou o discurso do MDES de um "anticolonialismo radical, logrando a eleição de vários conselheiros municipais, departamentais e regionais" (GRANGER, 2016: 170).

Numa outra perspectiva, tanto esse movimento quanto a central sindical UTG foram taxados pelos adversários de "populistas", sob o argumento de fomentarem o ódio racial ao reivindicarem maior poder aos negros e pardos em relação aos brancos. No decorrer dos anos 1990 e 2000, o MDES caminhou para um discurso mais amplo voltado também para os indígenas e imigrantes.

Em 2010, o governo central promoveu um plebiscito a respeito da independência, com três opções de votos: permanência do estatuto de então, fusão dos conselhos ou autonomia dentro da República, essa última sendo rechaçada por mais de 70\% dos eleitores (GRANGER, 2016: 172). A fusão dos conselhos aprovada resultou, a partir de 2015, na transformação do departamento em uma "Coletividade Territorial", com a eleição de seu primeiro presidente, Rodolphe Alexandre.

\section{Considerações Finais}

A tentativa de analisar uma região sul-americana díspar do restante do sub-continente através de um conceito bastante utilizado para a história deste último se demonstrou complexa e problemática. Potencializados inclusive com a ambição de abarcar dois países independentes, com suas particularidades, e uma região heterônoma pertencente a França.

Na Guiana, o período entre a declaração da independência, em 1966, até a proclamação da República Cooperativa, em 1970, foi marcado por uma crise de hegemonia política, uma vez que o novo governo não melhorou o nível de vida da maioria da população e nem integrou setores populares na administração do Estado. A dificuldade de inserção internacional alimentou a crise econômica interna, fomentando os descontentamentos populares, canalizados por instituições forjadas na confluência das tradições do trabalhismo inglês com o socialismo marxista.

Buscando solucionar esses problemas, em ordem de permanecer no controle da nação, Forbes Burnham optou por uma aliança retórica popular, nacionalizando e estatizando algumas empresas, voltando sua política externa para o bloco não alinhado e para Cuba. A meu juízo, uma tentativa de legitimação através da manipulação/atendimento de demandas dos trabalhadores, na medida em que o governo das classes tradicionais através da democracia liberal havia sido rechaçado.

O Suriname, nação surgida em 1975, não deu conta do atendimento de demandas populares, e nem da inclusão no mercado de trabalho e do consumo das classes subalternas. 0 sistema político herdado do período colonial não se mostrou suficiente para o controle social, sendo substituído a partir de 1980 pelo protagonismo de jovens militares que progressivamente costuraram alianças com partidos populares e se afastaram dos políticos tradicionais. No meu entender, podemos categorizar a retórica socialista, nesse caso, enquanto uma prática populista, de legitimação dos novos donos do poder que de alguma forma contemplou os subalternos.

A política externa heterodoxa e o autoritarismo interno fizeram parte da lógica do regime, esboçando em alguns momentos facetas marcantes de populismos latino-americanos. A base 
estreita da economia surinamesa não permitiu um tempo alargado para essa diretriz governamental, daí a rápida reviravolta e abandono dos referenciais contra-hegemônicos e desafiantes ao mercado internacional. Bouterse seguiu no poder, ao custo da desarticulação da aliança com os setores populares. Tensionado o ambiente, a saída do contexto foi uma guerra civil que contribuiu ainda mais para o atraso da estrutura econômica e política da jovem nação.

Na Guiana Francesa, o caminho foi glosar o trabalho de Granger, em busca da exposição de algumas características peculiares da história política desse pedaço de União Europeia na região amazônica. Em se tratando de um espaço não independente, certamente vetores caros ao populismo quedaram ausente, embora outros puderam ser enfrentados teoricamente sob o conceito de práticas populistas.

Com a ausência de elementos clássicos, já apontados, como aumento de salários para a classe trabalhadora, transferência de renda e poder dos sindicatos no aparelho de Estado, podemos concluir que o populismo na Guiana e no Suriname se resumiu muito mais a retórica do que a realidade. Como apontou Jorge Ferreira, no comentário das ideias de Gino Germani, "a passagem de uma sociedade tradicional para uma moderna ocorreu em um rápido processo de urbanização e industrialização, mobilizando, dessa maneira, as 'massas populares', substrato indispensável para o populismo na prática" (FERREIRA, 2001, p. 64). Não se pode afirmar que nos anos 1970 esse tipo de contexto tenha se dado na região em questão, que não protagonizou industrialização/urbanização acelerada.

Tampouco na sinalização de Capelato, de que o populismo latino-americano enquanto prática tenha respondido ao contexto de avanço do comunismo e do nazismo nos anos 1930, já que tratamos aqui de uma outra conjuntura histórica, com coordenadas bastante diversas (CAPELATO, 2001, p. 128). A questão, nesse sentido, seria a Guerra Fria, e as possibilidades de barganha de pequenos Estados através da manipulação de alianças e ameaças nacionalistas.

De sorte que um balanço crítico da "experiência populista" nas Guianas se assenta em bases frágeis, se limitando, a meu juízo, na estratégia possível para que Burnham e Bouterse pressionassem o Ocidente, buscando melhores posições políticas e econômicas. Ao mesmo tempo, produziram respostas a determinadas aspirações do campo de força interno logrando, dessa forma sustentação no poder por anos a fio, ao preço de uma pressão social avolumada.

(Recebido para publicação em novembro de 2017)

(Reapresentado em janeiro de 2018)

(Aprovado para publicação em abril de 2018)

\section{Cite este artigo}

CAVLAK, Iuri. Pensar o Populismo nas Guianas: Limites e Possibilidades. Revista Estudos Políticos: a publicação semestral do Laboratório de Estudos Hum(e)anos (UFF). Rio de Janeiro, Vol. 9 |N.1, pp. 160 -176, julho de 2018. Disponível em: http://revistaestudospoliticos.com/

\section{Bibliografia}

AGGIO, Alberto. "A Emergência de Massas na Política LatinoAmericana e a Emergência do Populismo". In: AGGIO, Alberto e LAHUERTA, Milton (orgs). Pensar o Século XX: problemas políticos e história nacional na América Latina. São Paulo: Editora da UNESP, 2003, pp. 137-164. ÁVILA, Carlos Federico Domínguez. "Guerra Fria na Região Amazônica: um estudo da Missão Venturini ao Suriname (1983)". In: Revista Brasileira de Política Internacional. N. 54, pp. 7-28, 2011. 
BANDEIRA, Moniz. Brasil, Argentina e Estados Unidos: Da Tríplice Aliança ao Mercosul. Rio de Janeiro: Editora Revan, 2003.

BROTHERSON JR, Festus. "The Foreign Policy of Guyana, 1970-1985: Forbes Burnham's Search for Legitimacy." In: Journal of Interamerican Studies and World Affairs. Vol. 31, n. 3. 1989. ( )

BURNHAM, Forbes. Declaration of Sophia: Addresss by Leader of PNC at a Special Congress of PNC. Plan. Sophia: Georgetown, 1974.

CAPELATO, Maria Helena. Populismo Latino-americano em discussão. In: FERREIRA, Jorge (org). O Populismo e Sua História: debate e crítica. Rio de Janeiro: Civilização Brasileira, 2001, p. 128.

CAVLAK, Iuri. Breve História do Suriname. Macapá/Rio de Janeiro: Editora da UNIFAP/Autografia, 2016.

CAVLAK, Iuri. História Social da Guiana. Macapá/Rio de Janeiro: Editora da UNIFAP/Autografia, 2016.

CHANDISINGH, Rajendra. "The State, the Economy, and Type of Rule in Guyana: An Assesment of Guyanais "Socialist Revolution". In: Latin America Perspectives. Vol. 10, n. 4. 1983. (http: // www.jstor.org/stable/2633448)

FERREIRA, Jorge. O nome e a coisa: o populismo na política brasileira. In: FERREIRA, Jorge (org). O Populismo e Sua História: debate e crítica. Rio de Janeiro: Civilização Brasileira, 2001, p. 64.

GARNER, Steve. Guyana 1838-1985: Etnicity, Class and Gender. Miami: Ian Randle Publishers, 2008.

GRANGER, Stéphane. "Nacionalismo e Identidade na Guiana Francesa: Um Populismo?" In: CHAVES, Daniel e PERLATTO, FERNANDO. Repensar os Populismos na América do Sul: debates, tradições e releituras. Macapá / Rio de Janeiro: Editora da UNIFAP / Autografia, 2016, pp. 158-178.

GRANGER, Stéphane. La Guyane et le Brésil, ou la Quête D'Integration Continentale D'Un Département Français d'Amérique. Tese de Geografia, Universidade de Paris 3. IHEL, 2012.

GOMES, Angela de Castro. "O Populismo e as Ciências Sociais no Brasil: Notas Sobre a Trajetória de um Conceito". In: FERREIRA, Jorge (org). O Populismo e Sua História: debate e crítica. Rio de Janeiro: Civilização Brasileira, 2001, pp. 17-58.

HOEFTE, Rosemarijn. Suriname in the Long Twentieth Century: Domination, Contestation, Globalization. New York: Palgrave Macmillian, 2014.

LIMA, Erick Cavalcanti Linhares. Política Externa do Vizinho Distante: Estudo de caso da República Cooperativa da Guiana. Brasília: Tese (Doutorado em Relações Internacionais) - Instituto de Relações Internacionais, Universidade de Brasília. Brasília, 171p, 2011.

MACKINNON, María e PETRONE, Mario. "Los Complejos de la Cenicienta." In: MACKINNON, María e PETRONE, Mario (orgs). Populismo y Neopopulismo en America Latina: el problema de la cenicienta. Buenos Aires, Editora da UBA, 1998, pp. 13-58.

PERLATO, Fernando. Adeus ao Populismo? Reviravoltas de um conceito e de uma política no Brasil do tempo presente. 
In: PERLATO, Fernando e CHAVES, Daniel. Repensar os Populismos na América do Sul: debates, tradições e releituras. Macapá / Rio de Janeiro: Editora da UNIFAP / Autografia, 2016.

RABE, Stephen. U.S. Intervention in British Guiana: A cold war history. Washington: North Carolina Press, 2005

THOMAS, Clive. "State Capitalism in Guyana: An Assessment of Burnham's Cooperative Socialist Republic." In: MACGOWAN, Winston, ROSE, James, GRANGER, David (orgs). Themes in African -Guyanese History. Hertford: Hansib Publications, 2009.

URT, João Nackle. "A lógica da construção de confiança: Relações Brasil-Suriname entre 1975 e 1985." In: Revista Brasileira de Política Internacional. N. 53, pp. 70-87, 2010. WOOFORD, Hazel. "The Origins of the Labour Movement." In: MACGOWAN, Winston, ROSE, James e GRANGER, David (orgs.) Themes in African-Guyanese History. Londres: Hansib Publications, 2009. 